\title{
Physician versus Patient Perception of Physician Hospital Discharge Communication: A Preliminary Study
}

\author{
Michael J. Maniaci', Michael G. Heckman², Nancy L. Dawson' \\ ${ }^{1}$ Division of Hospital Internal Medicine, Mayo Clinic, Jacksonville, USA \\ ${ }^{2}$ The Biostatistics Unit, Mayo Clinic, Jacksonville, USA \\ Email: maniaci.michael@mayo.edu
}

Received 16 September 2014; revised 15 October 2014; accepted 15 November 2014

Copyright (C) 2014 by authors and Scientific Research Publishing Inc.

This work is licensed under the Creative Commons Attribution International License (CC BY).

http://creativecommons.org/licenses/by/4.0/

\section{(c) (i) Open Access}

\section{Abstract}

Background: Physician discharge instructions are critical to patient care because they are the link transitioning the hospital care plan to the home. We hypothesize that physician perception of discharge instructions communication is better than patient perception. Objective: In a preliminary study, to compare patient and physician perception of communication at discharge. Design: Observational, survey-based. Setting: 330-bed adult teaching hospital. Participants: Surveys were mailed to 100 patients discharged home and 49 internal medicine physicians responsible for those patients' care. Each physician had between 1 and 4 patients surveyed. Measurements: Patients and physicians received anonymous 5 -item questionnaires concerning physician communication at discharge. Patient surveys inquired about their physicians' communication at the specific physician encounter, while physician surveys asked about the physicians' overall self-perception of discharge communication skills. Results: Completed questionnaires were returned by 59 patients and 40 physicians. Physicians reported a noticeably better perception of communication than their patients regarding spending adequate time reviewing the discharge plan $(83 \% \mathrm{vs.} 61 \%$, $P=0.027)$, speaking slowly enough to understand $(98 \%$ vs. $80 \%, P=0.013)$, using wording that could be easily understood $(100 \%$ vs. $68 \%, P<0.001)$ and taking time to answer questions before discharge $(85 \%$ vs. $59 \%, P=0.008)$. Perception of discharge communication improved with physician experience for several survey items. Conclusions: This study provides evidence suggesting that physician perception of communication at discharge is better than patient perception. Future studies of larger sample size and direct patient-physician pairing focusing on patient satisfaction and outcomes are needed.

\section{Keywords}

Communication, Patient Discharge, Questionnaire 


\section{Introduction}

Adequate communication between the health care providers and the hospitalized patients at discharge is a cornerstone of the practice of medicine. During the discharge process, the hospital course is summarized, the discharge diagnosis defined and the outpatient care plan reviewed. However, this may be the period when patients have the most difficult gathering and understanding the medical information provided [1]. Patients have reported trouble with communication at discharge with physicians often unaware of this problem [2] [3].

To reduce adverse events after discharge and decrease of readmission rates, investigators have recently focused on reorganizing the aspects of the discharge process [4] [5]; however, few studies have looked at the basics of the physician-patient interaction itself, i.e. flow of speech, use of medical jargon and use of adequate time in patient communication.

We hypothesize that a discrepancy exists between the perceptions of patients and those of their physicians regarding discharge communication, with physicians perceiving better communication than patients. To test this theory, we separately surveyed hospitalized patients after discharge and the physicians who were involved in discussing those patients' discharge plans. The primary aim of this preliminary study was to compare patient and physician perspectives on technical aspects of the discharge conversation. A secondary aim was to explore whether physician perspectives were associated with training level.

\section{Methods}

\subsection{Questionnaire Origin and Development}

Prior to study initiation, we reviewed our hospital patient satisfaction data and identified complaints related to communication. The categories that we chose to focus on in our questionnaire were the 3 most common areas of patient complaints. These were perception of time spent with the physician at discharge, the use of confusing medical jargon, and problems with understanding based on physician speech flaws. From these categories, four yes/no questions were developed for inclusion in the questionnaires to patients and physicians, as well as an additional question regarding need for physician communication training. Information regarding training level was also collected on physician questionnaires because we felt from previous experience that this could influence survey answers. After development of both questionnaires, sample questionnaires were preliminarily distributed to a group of patients and physicians in order to obtain feedback on question clarity and content. We then used this input to revise and develop the final study questionnaires. Patient and physician questionnaires are shown in Box 1 and Box 2, respectively. The wording of the patient and physician surveys were not identical, as they were tailored to the respondent, however themes were similar. Questions on patient surveys refer to the specific patient-physician encounter, while questions on the physician surveys inquired about general attitudes of communications skills at discharge during the study period.

\subsection{Setting and Study Population}

The present study was conducted in a 330-bed, adult teaching hospital. All patients and physicians included in the study were on the Internal Medicine Teaching Service. Beginning on January 1, 2008, the first 2 patients discharged from the Internal Medicine Teaching Service each day who spoke English as their primary language were chosen to receive the survey questionnaire, which was mailed to their home approximately one week after discharge. This process was continued until 100 patient surveys were mailed. The targeted sample size of 100 patients was chosen as it was to be reasonable for this preliminary study, and was not based on any formal power calculations. No discharge diagnosis was excluded. All attending staff and resident physicians serving on the Internal Medicine Teaching Service who discharged a study patient were sent a survey questionnaire through intra-office mail; these questionnaires were sent approximately 1 week after the physician's rotation on the service ended. A total of 49 physician questionnaires were sent. Twenty physicians had 1 patient surveyed, 11 had 2 patients surveyed, 14 had 3 patients surveyed, and 4 had 4 patients surveyed. Each patient and physician questionnaire was accompanied by a cover letter that explained the purpose of the study, confirmed that it was both voluntary and anonymous, and instructed the participant to answer each question directly without giving any additional information. Questionnaires were anonymously returned to the study investigators in addressed pre-stamped envelopes. The study was approved by the Mayo Clinic Institutional Review Board (IRB). 
Box 1. Questionnaire provided to patients.

1. On the day you left the hospital, do you feel that your doctor spent enough time discussing your medical plan with you?

YES, I feel enough time was spent.

NO, I feel the doctor should have spent more time.

2. Did the doctor speak slowly enough for you to understand him/her?

YES, the doctor spoke slowly enough for me to understand.

NO, the doctor spoke too quickly.

3. Was your medical plan explained to you in wording that you could understand?

YES, I understood the words the doctor used.

NO, the doctor used too many medical terms that I did not understand.

4. Did the doctor take the time to answer your questions before you left the hospital?

YES, the doctor answered all my questions.

NO, I still had questions after the doctor left.

5. Do you think that your doctor needs more training on patient communication?

YES, more training would help him/her communicate better.

NO, he/she does not need more training.

6. Did you have any trouble reading the words on this form?

YES, the wording on this form was complicated and I had trouble understanding it.

NO, I was able to read this form without any problems.

Box 2. Questionnaire provided to physicians.

1. Do you feel that you spend adequate time reviewing the discharge plan with a patient leaving the hospital?

YES NO

2. Do you feel that you speak slowly and clearly when you speak to a patient?

YES NO

3. When discussing a discharge plan with a patient, do you feel that you use wording that they can understand easily?

YES NO

4. On the day of discharge, do you always answer all of your patient's questions before they leave the hospital?

YES NO

5. Do you think that you would benefit from additional training on patient communication?

YES NO

6. What is your current training level?

PGY1 PGY2 PGY3 PGY4 Attending Physician

\subsection{Data Collection}

The last survey was returned on April 12, 2008. A total of 59 patients and 40 physicians completed and returned the questionnaires. Of these 40 physicians, 12 were first-year residents, 7 were second-year residents, 6 were third-year residents, 1 was a fourth-year resident, and 14 were attending-physicians. Only one patient (1.7\%) reported trouble reading the questionnaire. As a result of the lack of patient identification on the returned surveys, no direct paring between patient and physician survey responses was possible, and it is not known how many patient surveys were returned for each specific physician. In addition, the exact socio-demographics of the patients who returned the completed surveys were unknown due to the lack of patient identification on the surveys as required by our IRB.

\subsection{Statistical Analysis}

To evaluate the study primary aim of comparing patient and physician responses for each survey question, we utilized Fisher's exact test, and also calculated 95\% confidence intervals (CIs) for the difference in the proportion of positive responses between physicians and patients for each question. A Cochran-Armitage trend test was used to investigate the association between physician responses and training level. $P$-values of 0.05 or less were considered statistically significant. 


\section{Results}

Table 1 shows patient and physician responses to each survey question. There was evidence of poorer perception of communication for patients compared to physicians for four of the five survey questions. More specifically, the proportion of positive responses was $22 \%$ lower for patients for the survey item "physician spends adequate time reviewing discharge plan" $(P=0.027), 18 \%$ lower for "physician speaks slowly enough to understand" $(P=0.013), 32 \%$ lower for "physician uses wording that can be easily understood" $(P<0.001)$, and $26 \%$ lower for "physician takes time to answer questions before discharge" $(P=0.008)$. There was no statistically significant evidence of a difference in the proportion of positive responses among patients and physicians for the survey item "physician would benefit from more training on patient communication" $(P=0.13)$.

Physician responses to each survey question according to training level are shown in Table 2. Positive responses increased as training level increased for the survey items "physician spends adequate time reviewing discharge plan" $(P=0.025)$ and "physician takes time to answer questions before discharge" $(P=0.018)$. Positive responses decreased as training level increased for the survey item "physician would benefit from more training on patient communication" $(P=0.003)$. There was no statistically significant evidence of an association between physician response and level of training for the 2 other survey items.

\section{Discussion}

The discharge plan is used to transit the patients' hospital care plan to the post-discharge setting and if this transition is not done adequately, it can lead to incorrect care, discontinuation of proper care or readmission. Improvements in physician communication with patients regarding discharge instructions have the potential to reduce post-hospitalization complications and readmission rates. Our preliminary study provides evidence suggesting that physicians perceive that their communication with patients at discharge is more complete and effect-

Table 1. Patient and physician survey responses.

\begin{tabular}{|c|c|c|c|c|}
\hline Survey Item & $\begin{array}{l}\text { Patients } \\
(\mathrm{N}=59)\end{array}$ & $\begin{array}{l}\text { Physicians } \\
(\mathrm{N}=40)\end{array}$ & $\begin{array}{l}\text { 95\% CI for Difference: } \\
\text { Physicians-Patients }\end{array}$ & $P$ Value $^{\mathrm{a}}$ \\
\hline $\begin{array}{l}\text { Physician spends adequate time reviewing discharge } \\
\text { plan }\end{array}$ & $36(61)$ & $33(83)$ & $3 \%$ to $37 \%$ & 0.027 \\
\hline Physician speaks slowly enough to understand & $47(80)$ & $39(98)$ & $5 \%$ to $30 \%$ & 0.013 \\
\hline Physician uses wording that can be easily understood & $40(68)$ & $40(100)$ & $19 \%$ to $45 \%$ & $<0.001$ \\
\hline $\begin{array}{c}\text { Physician takes time to answer questions before } \\
\text { discharge }\end{array}$ & 35 (59) & $34(85)$ & $7 \%$ to $41 \%$ & 0.008 \\
\hline $\begin{array}{l}\text { Physician would benefit from more training on patient } \\
\text { communication }\end{array}$ & $24(41)$ & $10(25)$ & $-16 \%$ to $32 \%$ & 0.13 \\
\hline
\end{tabular}

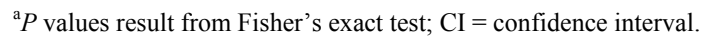

Table 2. Physician survey responses according to level of training.

\begin{tabular}{|c|c|c|c|c|}
\hline \multirow[b]{2}{*}{ Survey Item } & \multicolumn{3}{|c|}{ Positive Responses, No. (\%) } & \multirow[b]{2}{*}{$P$ Value $^{\mathrm{a}}$} \\
\hline & $\begin{array}{c}\text { First-Year } \\
\text { Residents }(N=12)\end{array}$ & $\begin{array}{l}\text { Second-Through Fourth-Year } \\
\text { Residents }(\mathrm{N}=14)\end{array}$ & $\begin{array}{l}\text { Attending Physicians } \\
\qquad(\mathrm{N}=14)\end{array}$ & \\
\hline $\begin{array}{l}\text { Physician spends adequate time } \\
\text { reviewing discharge plan }\end{array}$ & $8(67)$ & $11(79)$ & $14(100)$ & 0.025 \\
\hline Physician speaks slowly enough to understand & $11(92)$ & $14(100)$ & $14(100)$ & 0.19 \\
\hline $\begin{array}{l}\text { Physician uses wording that can } \\
\text { be easily understood }\end{array}$ & $12(100)$ & $14(100)$ & $14(100)$ & 1.00 \\
\hline $\begin{array}{c}\text { Physician takes time to answer questions } \\
\text { before discharge }\end{array}$ & $8(67)$ & $12(86)$ & $14(100)$ & 0.018 \\
\hline $\begin{array}{l}\text { Physician would benefit from more } \\
\text { training on patient communication }\end{array}$ & $7(58)$ & $2(14)$ & $1(7)$ & 0.003 \\
\hline
\end{tabular}

${ }^{\text {a } P}$ values result from a Cochran-Armitage trend test. 
tive than that perceived by patients regarding adequate time spent reviewing the discharge plan, speaking slowly enough to understand, using wording that can be easily understood and taking the time to answer questions before discharge.

Virtually all physicians surveyed stated that their speech pattern was clear and slow (98\%), while only $80 \%$ of patients held the same opinion. Although we did not specify particular speech pattern deficits in our study, it is known that both clarity of speech and tone of voice determine adequate speech patterns. Effective choice of wording - using concrete and descriptive words rather than abstract or ambiguous ones - improves the clarity of communication. Use of familiar language and concise wording may also help prevent listener confusion. Tone of voice is important because of the variable hearing ability among patients and thereby the need to adjust voice volume accordingly. Accents, whether of the physicians or the patients, may also make understanding difficult.

These barriers can be overcome by slowing speech or by repeating complex words or phrases to clarify potential areas of confusion for the patients. A usual conversation rate is approximately 150 words per minute. A normally functioning brain is able to comprehend up to 300 words per minute [6]; however, many factors can lower this ability. With normal aging, the ability to keep comprehension at this rate declines considerably [7]. Complexity of medical terms and such patient factors as illness, level of consciousness, use of sedating medications and age can all cause the rate of comprehension to decrease substantially. In contrast, slowing the patientphysician conversation rate can aid in overall comprehension. To account for these hindrances, physicians can choose their words carefully, be attentive to their own voice and use slow speech patterns when discussing health information with a patient.

Every physician surveyed (100\%) felt that they used wording easily understood by the patient, but only $68 \%$ agreed. Studies have shown that language common only to medical professionals, known as medical jargon, is recognized as a major inhibitor to effective patient-physician communication [8]. Our results showed that physicians are often oblivious to this language barrier. Castro et al. [9] found that $81 \%$ of encounters between patients and physicians involved the use of medical jargon. In this study, the patients showed a clear lack of understanding of common medical terms, all of which were key to their understanding of their medical care plan. The California Health Literacy Initiative also found that patients had a difficult time understanding their physicians because of medical jargon, and this difficulty led to a clear disruption in shared medical decision making [10]. Most patients in this initiative's study had trouble with simple understanding despite their ethnic background or education level. Ongoing physician education emphasizing the avoidance of medical jargon use with patients is needed, beginning in medical school and continuing throughout their careers.

Of the physicians surveyed, $85 \%$ reported that they took adequate time to answer patient questions and $83 \%$ felt that they spent adequate time reviewing the entire discharge plan with the patients, yet only about $60 \%$ of the patients agreed with these two statements. We found a correlation with physician training level on these two issues, with all of the attending staff $(100 \%)$ believing that they spent adequate time answering questions and reviewing the plan while only $67 \%$ of first-year residents believed that this was the case. This response may indicate that although new trainees recognize the constraints of time placed on patient-physician interaction, recognition of these constraints decreases as physician experience increases.

Studies have also shown that the lower a patient's health literacy, the lower the likelihood that the patient will ask questions [11]. Thus, patients who have the least understanding are the least likely to ask for clarification, putting them at increased risk for improperly following discharge instructions. Furthermore, when these patients do ask questions, the questions are usually concrete and functional ones (e.g., "When do I take this pill?"), as opposed to challenging or intuitive (e.g., "What is the diagnosis that requires me to take this medication?") [12], thus lessening the impact of the patient-physician conversation on their overall medical knowledge.

As seen in our study, the physicians with the most experience have the least realization of adequate patient instruction time. The California Health Initiative found that about two-thirds of the time, physicians did not recognize a patient's struggle with literacy [10]. Even when the provider recognizes that these barriers exist, the patient may deny or hide his or her deficiencies in comprehension because of shame [13], and the provider may find it difficult to overcome these hurdles without providing the adequate time and effort needed to ease the patient's anxiety.

Physicians may not recognize that common patient characteristics may indicate low health literacy, including male sex, lack of a high school education, age greater than 60 years, low socioeconomic class, recent immigration and English as a second language [14]. Positive body language and a nonthreatening tone of voice can encourage questions from a listener. When discussing comprehension with a patient, the health care provider should 
be open and nonjudgmental, admit that the discussion of health care can be confusing and reassure the patient that incomplete medical comprehension is not a unique problem. Mika et al. [15] found that using repetition when encouraging questions helped build patient questioning skills.

Finally, we found that more patients than physicians ( $41 \%$ vs. $25 \%)$ felt that physician education on effective communication would be useful. Of the physicians who felt that training would be useful, most $(70 \%)$ were first-year residents. These results are consistent with the findings in the other question area of the survey.

There are several limitations of our preliminary study. The first among these is the lack of direct pairing between patient and physician surveys. As such, we can only make general comparisons of perception of communication between the patients and physicians surveyed. A second limitation is the fact that some physicians had surveys sent out to one of their patients; others had two, three or four. This imbalance has the potential to bias results if the physicians who had more surveys sent to their patients had systematically better or poorer communication skills. As patients are included in study in a random fashion, this bias is unlikely. Related to this limitation, due to the lack of patient identification on patient surveys, it is unknown how many patient surveys were returned for each specific physician. A third limitation is that patient surveys inquired about a specific physician encounter, while physician surveys inquired about overall communication skills over the study period. It is our opinion that a physician's assessment of their overall communication at discharge is likely to be reflective of their communication at discharge for the patients surveyed, especially given that physician surveys were sent out at a time point close to their encounters with the patients who were surveyed. However, we acknowledge that inquiring about physician perception of communication for a specific patient encounter will be ideal. A fourth limitation is the small sample size, which results in low power to detect differences between groups and a lack of precision in the estimation of the magnitude of these differences. We anticipated a better survey return rate from our patient pool and when only $59 \%$ of the surveys were returned, we considered sending out an additional 100 surveys to increase our return rate and power, but we eventually elected against this due to survey time constraints. Finally, we acknowledge that those with negative opinions on the subject material are more likely to complete the survey, and this bias may have influenced the results.

In summary, the results of this preliminary study provide evidence suggesting that physician perception of communication at discharge is better than patient perception and that this difference may be greater for experienced physicians. In today's health care environment and cost-constraint dialogue, time spent with patients is becoming increasingly limited and has been undervalued as a part of quality improvement of health care delivery. Although discussions on major changes in health care access and payer sources are in the forefront of government agendas, the value of time spent with patients - with attention to results, such as in this study — should be an integral part of any health care initiative. Future studies that improve upon our limitations and focus on both patient satisfaction and outcomes are required to address this important issue.

\section{References}

[1] Makaryus, A.N. and Friedman, E.A. (2005) Patients' Understanding of Their Treatment Plans and Diagnosis at Discharge. Mayo Clinic Proceedings, 80, 991-994. http://dx.doi.org/10.4065/80.8.991

[2] Calkins, D.R., Davis, R.B., Reiley, P., Phillips, R.S., Pineo, K.L., et al. (1997) Patient-Physician Communication at Hospital Discharge and Patients' Understanding of the Postdischarge Treatment Plan. JAMA Internal Medicine, 157, 1026-1030. http://dx.doi.org/10.1001/archinte.1997.00440300148014

[3] Forster, A.J., Murff, H.J., Peterson, J.F., et al. (2003) The Incidence and Severity of Adverse Events Affecting Patients after Discharge from the Hospital. Annals of Internal Medicine, 138, 161-167. http://dx.doi.org/10.7326/0003-4819-138-3-200302040-00007

[4] Jack, B.W., Chetty, V.K., Anthony, D., et al. (2009) A Reengineered Hospital Discharge Program to Decrease Rehospitalization: A Randomized Trial. Annals of Internal Medicine, 150, 178-187. http://dx.doi.org/10.7326/0003-4819-150-3-200902030-00007

[5] Kripalani, S., LeFevre, F., Phillips, C.O., et al. (2007) Deficits in Communication and Information Transfer between Hospital-Based and Primary Care Physicians: Implications for Patient Safety and Continuity of Care. JAMA, 297, 831841. http://dx.doi.org/10.1001/jama.297.8.831

[6] Barron, A. (2004) Auditory Instruction. In: Jonassen, D.H., Ed., Handbook of Research on Educational Communications and Technology, 2nd Edition, Lawrence Erlbaum, Mahwah, 949-978.

[7] Wingfield, A., McCoy, S.L., Peelle, J.E., et al. (2006) Effects of Adult Aging and Hearing Loss on Comprehension of Rapid Speech Varying in Syntactic Complexity. Journal of the American Academy of Audiology, 17, 487-497. 
http://dx.doi.org/10.3766/jaaa.17.7.4

[8] Castro, C.M., Wilson, C., Wang, F. and Schillinger, D. (2007) Babel Babble: Physicians' Use of Unclarified Medical Jargon with Patients. American Journal of Health Behavior, 31, S85-S95.

[9] Castro, C.M., Wilson, C., Wang, F., et al. (2007) Babel Babble: Physicians' Use of Unclarified Medical Jargon with Patients. American Journal of Health Behavior, 31, S85-S95. http://dx.doi.org/10.5993/AJHB.31.s1.11

[10] Bennett, D. (2003) Low Literacy, High Risk: The Hidden Challenge Facing Health Care in California: Executive Summary [Internet]. The California Health Literacy Initiative: A Project of California Literacy, Inc., Pasadena. http://cahealthliteracy.org/pdffiles/healthliteracy2.pdf

[11] Katz, M.G., Jacobson, T.A., Veledar, E., et al. (2007) Patient Literacy and Question-Asking Behavior during the Medical Encounter: A Mixed-Methods Analysis. Journal of General Internal Medicine, 22, 782-786. http://dx.doi.org/10.1007/s11606-007-0184-6

[12] Davis, R.E., Koutantji, M. and Vincent, C.A. (2008) How Willing Are Patients to Question Healthcare Staff on Issues Related to the Quality and Safety of Their Healthcare? An Exploratory Study. BMJ Quality \& Safety, 17, 90-96. http://dx.doi.org/10.1136/qshc.2007.023754

[13] Parikh, N.S., Parker, R.M., Nurss, J.R., et al. (1996) Shame and Health Literacy: The Unspoken Connection. Patient Education and Counseling, 27, 33-39. http://dx.doi.org/10.1016/0738-3991(95)00787-3

[14] Kripalani, S. and Weiss, B.D. (2006) Teaching about Health Literacy and Clear Communication. Journal of General Internal Medicine, 21, 888-890.

[15] Mika, V.S., Wood, P.R., Weiss, B.D., et al. (2007) Ask Me 3: Improving Communication in a Hispanic Pediatric Outpatient Practice. American Journal of Health Behavior, 31, S115-S121. http://dx.doi.org/10.5993/AJHB.31.s1.15 
Scientific Research Publishing (SCIRP) is one of the largest Open Access journal publishers. It is currently publishing more than 200 open access, online, peer-reviewed journals covering a wide range of academic disciplines. SCIRP serves the worldwide academic communities and contributes to the progress and application of science with its publication.

Other selected journals from SCIRP are listed as below. Submit your manuscript to us via either submit@scirp.org or Online Submission Portal.
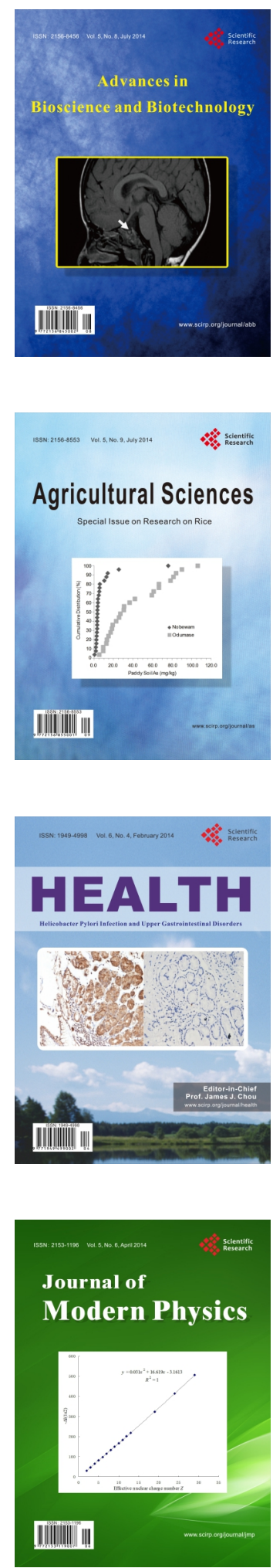
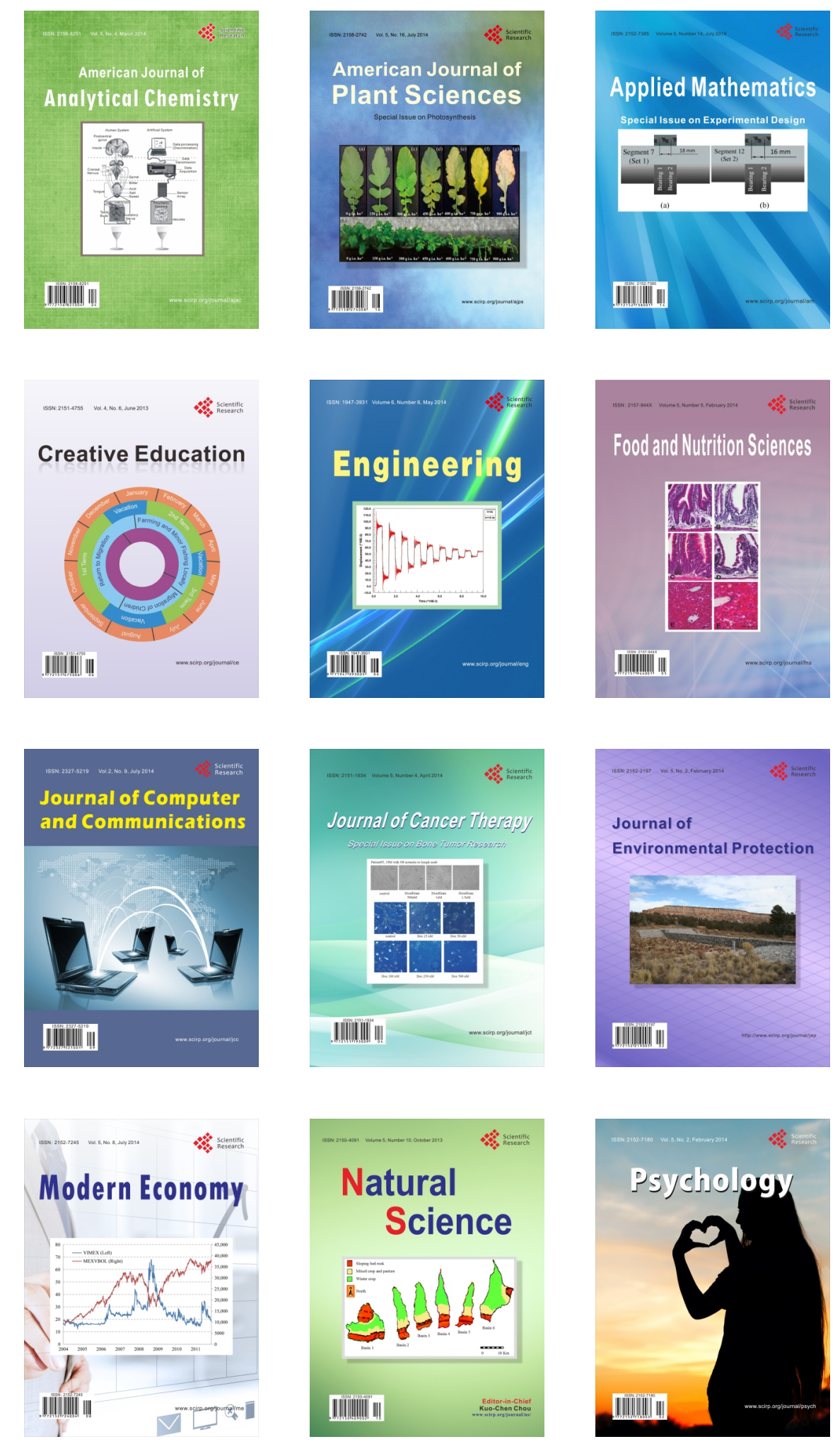